\title{
REFORMULAÇÕES DO ENSINO MÉDIO
}

\author{
C. J. FERRETI \\ Universidade Tecnológica Federal do Paraná -UFTPR \\ celsojoaoferretti@gmail.com
}

Artigo submetido em agosto/2016 e aceito em setembro/2016

DOI: $10.15628 /$ holos.2016.4988

\section{RESUMO}

Este texto aborda a reformulação do Ensino Médio, proposta nos anos recentes por meio do PL 6840, apresentado em Comissão Especial de Educação da Câmara Federal, em 2013. O PL 6840 tem um texto hibrido que, face às críticas, extirpou formulações mais polêmicas, incorporou elementos das Diretrizes Curriculares Nacionais para o Ensino Médio aprovadas em 2011, mas não abriu mão do que era mais caro a seus propositores: a escolarização em tempo integral e o desenvolvimento do ensino médio tendo em vista não prioritariamente a formação básica, politécnica e omnilateral, em suma, a formação efetivamente integral, mas a de caráter mais específico e imediatista, tendo em vista, num primeiro momento, o encaminhamento para os cursos superiores e, ao final, a contribuição para as demandas que interessam à economia capitalista.

PALAVRAS-CHAVE: Ensino Médio, PL 6.840, Educação.

\section{HIGH SCHOOL REFORMULATIONS}

\section{ABSTRACT}

This text approaches the reformulations in High School, proposed in recent years through PL 6840 (law project), presented at Special Committee at the National Congress in 2013. This project has a hybrid text that, facing criticism, removed more polemical formulations, included elements from High School National Curricular Directives approved in 2011. However, it did not abandon the most expensive parts to its proposers: full time school and the development of high school aiming not specifically at basic, polytechnic and omnilateral formation. Thus, it proposes an effective integral formation focusing more specifically and immediately, first on the procedures for college courses, then contributions for demands that interest to the capitalist economy.

KEYWORDS: High School, PL 6.840, Education. 
Este texto está voltado à discussão da reformulação do Ensino Médio, proposta nos anos recentes por meio do PL 6.840, apresentado em Comissão Especial de Educação da Câmara Federal em 2013. Para fazê-lo parece desejável, inicialmente, retomar as diferentes reformulações pelas quais passou esse nível de ensino no Brasil, designado por várias denominações conforme o momento histórico, pois esse movimento poderá contribuir para o melhor entendimento do que ora é proposto.

O primeiro aspecto a salientar é o de que as diferentes reformulações ocorridas nesse nível de ensino ao longo da história da educação brasileira referiram-se, predominantemente, à estrutura e conteúdo do currículo, ainda que outros aspectos também tenham sido abordados como, por exemplo, o financiamento. Nesse sentido, o foco privilegiado será o das reformulações curriculares, situando-as, tanto quanto possível, nos contextos sociais e políticos próprios.

No que respeita ao período 1920-1960 tomaremos como referência o texto de Souza (2009) a respeito da configuração do ensino secundário. Os primórdios do que hoje conhecemos por Ensino Médio remetem à Lei Orgânica do Ensino Secundário (Decreto-Lei n. 2.244, de 9 de abril de 1942) por meio da qual a Reforma Capanema, seguindo, de certa forma, a Reforma Francisco Campo, manteve a divisão do Ensino Secundário em dois ciclos, mas com modificações em cada um deles. O primeiro ciclo, ou ginasial, que na Reforma Campos tinha a duração de 5 anos passou a 4 anos. O segundo ciclo, que naquela reforma era denominado de complementar e já previa a diversificação formativa tendo em vista o ensino superior, sofreu mudança mais profunda. Além de alterar sua duração de 2 para 3 anos, a Reforma Capanema subdividiu esse ciclo, que passou a denominar-se colegial, em 2 cursos paralelos e de mesma duração, o clássico e o científico, contemplando, portanto, como na reforma Francisco Campos, a diversificação curricular e a continuidade de seus estudos em nível superior. De acordo a referida Lei em seu artigo 4으, no "curso clássico [concorreriam] para a formação intelectual, além de um maior conhecimento da filosofia, um acentuado estudo das letras antigas". Já no curso científico, "tal formação [seria] marcada por um estudo maior das ciências".

A divisão do colegial em dois cursos tem por detrás de si um intenso debate que, conforme Souza (2009), remonta às discussões travadas desde o século XIX e acirradas na década de 1920, em função dos questionamentos produzidos por intelectuais às ênfases referentes às humanidades clássicas no ensino secundário face às necessidades e demandas de uma sociedade que estaria se modernizando e reclamando maior atenção aos conhecimentos de natureza científica. De acordo com a autora, nessa década e nas posteriores:

as disputas em torno do currículo colocaram em questão a legitimidade da cultura humanista predominante em confronto com a educação científica cada vez mais valorizada. Os ataques mais veementes recaíram sobre os estudos clássicos Latim e Grego, mas, de um modo geral, todo o ensino das humanidades esteve sob contestação. (SOUZA, 2009, p. 73)

A polêmica, segundo Souza, mobilizou intelectuais e educadores em defesa das duas posições que se contrapunham, com nuances no interior de cada uma delas, versando não apenas sobre seus fundamentos, mas contemplando também proposições específicas em torno do que seria desejável para o desenvolvimento tanto do campo das humanidades quanto do das ciências. Segundo se depreende do estudo da autora, a discussão no âmbito das humanidades e em defesa 
de sua valorização era marcada pelo ponto de vista do catolicismo. Souza (2009, p. 75) assim se refere aos argumentos de um de seus representantes:

A questão de fundo (...) era mais ampla e dizia respeito a uma concepção de sociedade e cultura impregnada de valores católicos contrários ao utilitarismo e ao pragmatismo da sociedade moderna. Para ele, os estudos secundários desempenhavam um papel importante na preservação da alta cultura. $O$ valor da educação secundária estava no seu acentuado desinteresse, isto é, seu apreço por uma formação geral sem preocupação com a especialização ou a formação profissional.

Percebe-se, neste caso, além da contraposição entre duas posições, a identificação do enfoque científico não apenas com o pragmatismo e o utilitarismo, mas também com a formação específica para o trabalho, em contraposição a uma formação de caráter amplo, calcado na cultura clássica em que se sobressaia o ensino do Latim.

A reforma Francisco Campos, desencadeada no início da década de 1930, acirrou o debate, pelo que se deduz do texto de Souza, principalmente em relação a dois aspectos que a marcaram: a divisão do ensino secundário em dois ciclos, conforme referido anteriormente e a adoção, no que tange ao currículo, de "uma clara opção pelos estudos científicos fixando uma distribuição mais equilibrada entre matérias literárias e científicas" (SOUZA, 2009, p. 77).

Em defesa da formação humanística várias manifestações ganharam corpo, segundo Souza, pelas vozes de setores da Igreja Católica e de professores de escolas particulares, a maior parte delas retomando os argumentos anteriormente brandidos pelos educadores católicos. A estes foram acrescentados outros, oriundos de professores secundaristas, segundo os quais a menor ênfase no ensino das humanidades e a maior presença das disciplinas científicas no currículo, sobrecarregando-o, promoviam a queda da qualidade do ensino, agravada, além disso, pela multiplicação das escolas secundárias.

Poucos, como Fernando de Azevedo, ponderaram que "a chave do problema do ensino secundário estava em equacionar sua finalidade adequando seu caráter intrínseco de educação da juventude com base numa cultura geral desinteressada com as necessidades de modernização da sociedade brasileira." (AZEVEDO, apud SOUZA, 2009, p. 79-80)

Os argumentos apresentados em defesa da ênfase no ensino das humanidades na perspectiva clássica oculta motivações integrantes das discussões anteriores, a saber, a de que tal defesa estava lastreada na manutenção de uma concepção educacional e de mundo que vinha sendo cultivada pela parcela restrita da população brasileira com acesso à escola secundária, geralmente de caráter privado, oferecida por instituições católicas. Tal defesa tinha, portanto, como referência, uma condição de classe. Não por acaso, o embate entre a formação humanística e a que enfatizava a formação científica deu-se no âmbito do processo de democratização da oferta do ensino secundário a setores de classe média e mesmo populares, antes excluídos dessa mesma oferta. A mesma motivação de classe aparentemente guiou, também, as opiniões contrárias à divisão do secundário em ciclos, se se considera a observação de Isambert-Jamati (1995, apud SOUZA, 2009, p. 77) "segundo a qual o ensino longo representou no ocidente um traço aristocrático simbolizando meios [de] que só dispunham os que podiam se dedicar a uma socialização refinada". Como observa Souza (idem, p. 84), valendo-se das considerações de Isambert-Jamati, 
a adesão das elites à cultura clássica e a rejeição à cultura moderna, sobretudo técnica, advinha de uma compreensão da educação secundária como símbolo de diferenciação social. O ideal de formação do homem polido, civilizado, cristão e culto encarnava toda a representação de uma educação de classe.

A Reforma Capanema encarregou-se, por meio da Lei Orgânica do Ensino Secundário, de promover, segundo Souza, a revitalização da formação humanística abalada pelos debates anteriores, ainda que mantendo e, como vimos anteriormente, aprofundando, a divisão do ensino secundário em dois ciclos e deste em dois tipos de curso. De acordo com a autora:

A reforma deu ênfase ao estudo do Latim ensinado em todas as séries do curso ginasial enquanto as ciências foram relegadas apenas a duas aulas semanais nas duas últimas séries desse ciclo [...] Vigente por quase duas décadas (entre $1942 \mathrm{e}$ 1961), no período marcante de expansão contínua do ensino secundário no país, as gerações de estudantes que frequentaram os ginásios e colégios brasileiros nas décadas de 1940 até meados dos anos 60, muitos deles provenientes da classe média e um número crescente de jovens pertencentes às camadas populares, tiveram contato não apenas com disciplinas e programas impregnados da cultura literária, mas com uma concepção de educação norteada pelos valores do humanismo prevalecentes na sociedade brasileira. (SOUZA, 2009, p. 81-82)

Ressaltando que, "para muitos intelectuais de tendência liberal tratava-se de alargar a compreensão do humanismo adequando-o aos desafios da sociedade moderna" (SOUZA, 2009, p. 83), embora sem abandonar as críticas à tendência de arrefecimento do humanismo clássico em benefício dos saberes científicos, associados, por alguns dentre eles, ao utilitarismo e ao pragmatismo, a autora toma por base principalmente o pensamento que Fernando de Azevedo vinha defendendo desde meados da década de 1920 para abordar o que considera o surgimento de um novo humanismo no âmbito das discussões sobre o ensino secundário no Brasil de meados do século XX. Tal humanismo, segundo Azevedo, fundava-se na concepção de que o importante seria a valorização e elevação do humano, cabendo, por isso, superar a dicotomia entre a cultura clássica e a científica, posto que ambas concorriam para tal elevação. Assim, o curso secundário a ser oferecido às classes médias deveria privilegiar a cultura geral, incorporando o conhecimento científico, mas sem atrelar-se às especializações. Como aponta Santos (idem, p. 86),

ficava claro nas posições do autor, que a ciência assumia um papel primordial na criação de um novo espírito humanístico e isso se devia aos seus inúmeros benefícios para a humanidade, a amplitude de sua ação social e à sua força dominadora em todos os campos de aplicação.

Cabe destacar que algumas especializações, não internas à formação de caráter geral, mas tendentes à profissionalização no nível de ensino correspondente ao médio, já haviam sido convenientemente deslocadas, em 1942, com as Leis Orgânicas da Reforma Capanema, para o Ensino Industrial, dividido, assim como o secundário, em dois ciclos, o segundo dos quais constituiu o Ensino Técnico Industrial. O mesmo ocorreu, entre 1943 e 1945, para o Ensino Comercial. Se, de um lado, o secundário deixou, aos poucos, de ser o curso predominantemente voltado à cultura clássica, passando a incorporar os conhecimentos de cunho científico, de outro, as Leis Orgânicas consagraram a dualidade entre a formação oferecida às classes médias e altas e às classes populares que marcou e ainda marca a educação brasileira. 
O capítulo seguinte desse processo remete à intensa discussão que se iniciou em 1948 com o encaminhamento ao Congresso da mensagem presidencial do projeto de lei relativo à constituição da primeira lei de Diretrizes e Bases da Educação Nacional, somente finalizada em 1961, com a promulgação de referida lei. O período é marcado, do ponto de vista da economia, pelas oscilações da burguesia entre o modelo de nacional-desenvolvimentismo assentado no capital nacional e, outro, estruturado por meio da participação e comando do capital estrangeiro tendo em vista a industrialização do país, Acirraram-se, nesse contexto, do ponto de vista educacional, os embates entre os setores sociais voltados à modernidade, encarnada no processo de industrialização, incluindo os educadores afinados com o projeto dos Pioneiros da Educação e os setores conservadores, articulados em torno do empenho da Igreja em manter o primado da concepção de educação que defendia, aliado aos interesses dos proprietários de escolas privadas, que se opuseram ao projeto de lei proposto pelo governo.

Os argumentos priorizados no debate já não eram relativos apenas à organização curricular, mas à democratização e descentralização do ensino, tendo em vista as mudanças demográficas em curso, decorrentes da industrialização e urbanização, bem como os referentes à criação do sistema nacional de educação cuja organização e gestão caberiam ao Estado. Enquanto parte dos congressistas alinhou-se com as teses dos Pioneiros da Educação em defesa da escola pública e laica, bem como da democratização e descentralização, os afinados com as teses da Igreja e das escolas privadas defenderam a liberdade das famílias em escolher as escolas onde matricular seus filhos, tendo em vista, de um lado, o fortalecimento e ampliação da formação religiosa católica a maior número de adolescentes e jovens e, de outro, a manutenção do ensino privado que cedia espaço ao ensino público. Por isso, rejeitavam a proposta de seus oponentes. A manifestação de Florestan Fernandes a respeito é lapidar:

Os pioneiros da educação nova tiveram a ideia de defender uma Lei de Diretrizes e Bases da Educação Nacional e ajudaram a elaborar um projeto que contribuiria poderosamente para uma revolução educacional. No entanto, educadores católicos e representantes das escolas privadas elaboraram um substitutivo, apresentado ao Congresso Nacional em nome do deputado Carlos Lacerda - e por aí se estabeleceram várias prioridades, várias precedências, em fins de 1961(...) Essa Lei representou um sério golpe no ensino público. (FERNANDES, 1989, p. 128)

No entanto, é necessário atentar para o que propunham os signatários do Manifesto dos Pioneiros, pois, se, de um lado, fazia sentido a crítica da elitização do ensino, de outro cabe prestar atenção às críticas relativas aos caminhos que se delineavam para o ensino secundário. Se é correto considerar que o avanço do conhecimento científico não poderia ser desconsiderado do ponto de vista da formação dos adolescentes e jovens, não é menos verdade que a crítica dos que viam nesse movimento concessões ao pragmatismo e ao utilitarismo precisaria ser levada em consideração, sob pena de, ao não fazê-lo, referendar posturas meramente adaptativas a processos sociais, políticos, econômicos e culturais em mudança nos meados do século XX em nome da qualidade do ensino. Em outros termos caberia que a formação a ser oferecida aos alunos levasse na devida conta a consideração reflexiva e crítica dessas mesmas transformações. Braghini (2005), em sua dissertação de mestrado tece considerações questionadoras a respeito a partir da análise da produção de intelectuais e educadores afinados com a concepção de qualidade proposta pelos colaboradores da Revista Brasileira de Estudos Pedagógicos entre 1952 e 1961, na seção Ideias e Debates, em que transparecia, segundo a autora, a intenção de: 
transformar o ensino secundário em um ensino prático, que desenvolvesse as competências específicas dos indivíduos, que formasse pequenas elites de classe média, que concedesse dignidade ao trabalho, com professores dignos e alunos modernos e estudiosos (...) que concediam qualificação à escola idealizada que, a partir desse período, seria também uma das agenciadoras do desenvolvimento. (BRAGHINI, 2005, p. 140)

Aparentemente, o calor dos debates sobre a educação no período não conseguiu toldar a tendência que já vinha se delineando desde a década de 1920, tendo em vista a priorização paulatina e constante do estabelecimento de relações cada vez mais estreitas entre as proposições educacionais e as expectativas demarcadas pela economia.

Do ponto de vista da organização curricular, a LDB promoveu a flexibilização e diversificação do currículo como é possível verificar pela redação dos seguintes excertos:

Título VII

CAPÍTULO I

(...)

Art. 34. O ensino médio será ministrado em dois ciclos, o ginasial e o colegial, e abrangerá, entre outros, os cursos secundários, técnicos e de formação de professôres para o ensino primário e pré-primário.

Art. 35. Em cada ciclo haverá disciplinas e práticas educativas, obrigatórias e optativas.

(...)

\section{CAPÍTULO II}

Art. 44. O ensino secundário admite variedade de currículos, segundo as matérias optativas que forem preferidas pelos estabelecimentos.

$\S 1$ O O ciclo ginasial terá a duração de quatro séries anuais e o colegial, de três no mínimo.

§ 2 ㅇ Entre as disciplinas e práticas educativas de caráter optativo no 1 e e 2 o ciclos, será incluída uma vocacional, dentro das necessidades e possibilidades locais.

(...)

Art. 46. Nas duas primeiras séries do ciclo colegial, além das práticas educativas, serão ensinadas oito disciplinas, das quais uma ou duas optativas, de livre escolha pelo estabelecimento, sendo no mínimo cinco e no máximo sete em cada série.

$\S 1$ A terceira série do ciclo colegial será organizada com currículo aspectos linguísticos, históricos e literários.

§ 2 A terceira série do ciclo colegial será organizada com currículo diversificado, que vise ao preparo dos alunos para os cursos superiores e compreenderá, no mínimo, quatro e, no máximo, seis disciplinas, podendo ser ministrada em colégios universitários.

A tensão entre a formação humanista clássica (ainda que menos acentuada) e a científica (tendencialmente valorizada) marcou o ensino secundário na década seguinte à promulgação da LDB 4024, no que concerne tanto ao 1 o quanto ao 2 o ciclo. Mas foi, de certa forma, atenuada por meio da flexibilização curricular decorrente da possibilidade da oferta de disciplinas obrigatórias, optativas e complementares. 
No segundo ciclo (colegial), apesar da LDB não se referir "explicitamente ao desdobramento [...] em dois cursos: clássico e científico [...], esse desdobramento foi conservado, mais ou menos nos mesmos moldes, talvez na totalidade das escolas secundárias do País" (WEREBE, 1968, p. 129). Segundo a autora, os cursos científicos, além de congregarem o maior número de estudantes, eram predominantemente frequentados por alunos do sexo masculino enquanto que nos cursos clássicos eram mais numerosas as alunas. Em sua opinião, tais fatos se deveriam, de um lado, a que os cursos científicos abririam mais possibilidades de ingresso em cursos superiores e, de outro, à "maior valorização dos estudos e carreiras ligados às ciências" (idem, p. 134) Tal diversificação acentuava-se nas terceiras séries dos cursos colegiais, pois estas se estruturaram visando à preparação dos alunos para os cursos superiores, de acordo com a perspectiva propedêutica do secundário. $^{1}$

Na época, a discussão sobre os rumos que deveria tomar o ensino secundário (tanto o 1 은 quando o 2 o ciclo) estava permeada pelo processo de democratização da oferta desse grau de ensino. A inserção na escola de adolescentes e jovens dos setores médios e populares contribuía para a crítica não apenas à formação humanista clássica, mas, também, para os procedimentos pedagógicos adotados nas escolas anteriormente frequentadas por aqueles oriundos da antiga aristocracia e das classes altas. Os argumentos eram de que tanto a concepção quanto a metodologia de ensino deveriam ser revistos. A primeira, por não se adequar aos processos de modernização e incipiente industrialização da sociedade brasileira. A segunda por não se mostrar adequada a sujeitos sociais cuja origem e cuja inserção social seriam muito diversa daquela a que se voltava a educação clássica.

Tais argumentos foram muito utilizados à época para, ao lado do reconhecimento da inexistência objetiva de condições para dar respostas adequadas à democratização e rápida expansão do ensino secundário, justificar, de um lado, e criticar, de outro, a qualidade desse ensino que se deteriorava no país. A crítica apontava para duas orientações que se tornavam cada vez mais claras: a necessidade da educação voltar-se para as necessidades e demandas criadas pela modernização e desenvolvimento da sociedade, assim como para a revisão dos métodos centrados no professor, tendo em vista a criação de mais liberdade e participação do aluno nas aulas, em alinhamento com as proposições da escola nova.

De acordo com Saviani (2008), a industrialização do início da década de 1960 foi marcado pelas disputas entre a perspectiva social e econômica marcada pela "ideologia nacionaldesenvolvimentista", da qual o Instituto Superior de Estudos Brasileiros (ISEB) era porta-voz, e a Escola Superior de Guerra (ESG) que tinha por referência a teoria da interdependência, alinhada com "a doutrina da segurança nacional". Para o autor,

Essas duas tendências eram incompatíveis entre si, mas no curso do processo o objetivo comum agregava grupos com interesses distintos, divergentes e até mesmo antagônicos. Nessas condições, a contradição permanecia em segundo plano, em estado latente, tipificando-se na medida em que a industrialização

\footnotetext{
${ }^{1}$ De acordo com Machado (1987, p. 132) na terceira série [dos cursos colegiais do Estado de São Paulo], os alunos poderiam optar por uma das seguintes áreas: "Ciências Humanas, Ciências Físicas e Biológicas, Ciências Contábeis e Administrativas, Letras, Artes, Educação, [cada uma delas comportando] seis disciplinas obrigatórias e uma optativa escolhida pelo estabelecimento."
} 
progredia, até emergir como contradição principal quando se esgotou o modelo de substituição de importações. (idem, p. 292)

Esta se manifestou por meio da polarização "entre aqueles que, à esquerda, buscavam ajustar o modelo econômico à ideologia política e os que, à direita, procuravam adequar a ideologia política ao modelo econômico" (ibidem, p. 293).

Outro elemento desse contexto manifestou-se por intermédio da crise política desencadeada no governo Jango Goulart em função da intenção do governo em promover as reformas de base iniciadas e interrompidas na gestão Kubitscheck. Tais reformas que cobriam um variado espectro da vida nacional (econômico-financeiras urbanas, administrativas, agrárias e universitárias, ampliação do direito de votos a setores antes excluídos dessa prática) tiveram o apoio de parcelas significativas da sociedade (classes médias, trabalhadores, empresários alinhados com o nacional-desenvolvimentismo). Simultaneamente o empresariado afinado com a perspectiva da interdependência mobilizou-se, juntamente com os militares, em oposição aos primeiros resultando disso o golpe militar de 1964 e a instauração da ditadura.

Esta promoveu modificações de monta na educação brasileira que atingiram não apenas o ensino secundário, mas, também, o superior, guiadas, em ambos os casos, pela intenção de adequá-los à concepção de país e de desenvolvimento econômico com as quais se afinavam os articuladores do referido golpe, ou seja, aquela ensejada pela doutrina da interdependência em contraposição à do nacional desenvolvimentismo, conforme Saviani (2008).

A reforma educacional que se produziu tanto no ensino superior quanto no ensino médio pautou-se pelos ditames e recomendações oriundas da Teoria do Capital Humano, de acordo com os quais a caberia encarar a educação como investimento financeiro cujos retornos se expressariam, em ambos os casos, pela formação eficiente e racional de profissionais que contribuíssem para o desenvolvimento econômico e social do país, sob o argumento de que este, para ganhar expressão e peso na economia internacional, necessitaria promover a formação rápida e urgente de trabalhadores qualificados. Embora longa, a citação a seguir se justifica, pois nela Saviani (2008, p. 296-297) expressa claramente o sentido da concepção de educação que orientou as reformas da época:

[Esta] se traduz pela ênfase nos elementos dispostos pela "teoria do capital humano"; na educação como formação de recursos humanos para o desenvolvimento econômico dentro dos parâmetros da ordem capitalista; na função de sondagem de aptidões e iniciação para o trabalho atribuída ao primeiro grau de ensino; no papel do ensino médio de formar, mediante habilitações profissionais, a mão-de-obra técnica requerida pelo mercado de trabalho; na diversificação do ensino superior, introduzindo-se cursos de curta duração, voltados para o atendimento da demanda de profissionais qualificados; no destaque conferido à utilização dos meios de comunicação de massa e novas tecnologias como recursos pedagógicos; na valorização do planejamento como caminho para racionalização dos investimentos e aumento de sua produtividade; na proposta de criação de um amplo programa de alfabetização centrado nas ações das comunidades locais. Eis aí a concepção pedagógica articulada pelo IPES, que veio a ser incorporada nas reformas educativas instituídas pela lei da reforma universitária, pela lei relativa ao ensino de 1 ㅇ e 2 ㅇ graus e pela criação do MOBRAL. 
No caso específico do ensino médio, a reforma consolidou-se na Lei 5692/1971, por meio da qual esse nível de ensino, além de outras alterações em sua estrutura, assumiu caráter compulsoriamente profissionalizante, ainda que não existissem, nas redes públicas de ensino, as condições físicas, de equipamentos e de professores suficientemente adequadas para tal fim. Coube a tais redes, assim como às privadas, a formação de auxiliares técnicos e técnicos nas mais diversas áreas, visando a qualificação para o trabalho e tendo por base perfis profissionais referenciados em habilitações profissionais muito específicas, conforme o parecer 45/72 do Conselho Federal de Educação. Para não dar a impressão de voltar-se apenas para as questões de ordem econômica e profissional o citado parecer faz uma breve incursão sobre as relações ente humanismo e tecnologia sugerindo que a legislação em pauta buscava superar a dicotomia que havia se manifestado em períodos anteriores entre a formação humanista e científica pela articulação entre elas, denominando tal formação de integral (sem que, no entanto se esclarecesse o sentido dos termos-chave: humanismo, conhecimento científico e integralidade).

Dadas as limitações anteriormente apontadas, as escolas das redes públicas adaptaram-se forçosamente às determinações legais oferecendo as habilitações profissionais que não exigissem, ou exigissem poucas mudanças na sua organização curricular. Multiplicaram-se nelas, por essa forma, as habilitações referentes ao setor terciário tais como secretariado, contabilidade, administração, etc. e, mais raramente, quando as escolas contavam com algum laboratório, ou acesso a eles, habilitações ligadas aos campos das ciências químicas ou biológicas, por exemplo. Já as escolas privadas que atendiam predominantemente a elite social se multiplicaram no período e continuaram mantendo seu foco na formação propedêutica, tendo em vista os vestibulares aos cursos superiores, acrescentando ao rol das disciplinas voltadas para tal fim, as optativas que tinham alguma relação com os cursos pretendidos no ensino superior e se afinavam com alguma habilitação de técnico ou auxiliar técnico compatível.

A manifestação contrária às especificações extremadas das habilitações profissionais e as dificuldades de sua implantação por parte das escolas, bem como a baixa aceitação, pelo empresariado, da formação oferecida, aliada à avaliação deste de que lhes seria mais econômico formar seus trabalhadores ao invés de contratar técnicos por valores mais altos, levou o governo a modificar o disposto no Parecer 45/1972 por meio de outro (Parecer 76/1975), também emitido pelo Conselho Federal de Educação em 1975, o qual flexibilizou o anterior, insistindo, todavia, na integração entre formação humanista e científica, apesar de continuar afirmando o primado da profissionalização.

Tal flexibilização consistiu, basicamente, em dois movimentos: a) substituir as habilitações específicas por habilitações básicas, de caráter mais geral, por áreas de atividade comuns a campos profissionais afins, ou famílias profissionais, a partir das quais poderia ocorrer, na trajetória da formação dos alunos, a especificação profissional; b) considerar que nem todas as escolas de 20 grau precisariam, necessariamente, profissionalizar, podendo várias delas se aglutinar em torno de centros interescolares onde tal profissionalização ocorreria. Pode-se também encontrar nesse parecer, sob o nome de intercomplementaridade, traços do que hoje constitui a forma concomitante de formação profissional de nível técnico.

Um último aspecto, mas não menos importante, deve ser considerado nesse processo. Um elemento de peso na promoção da reforma universitária de 1968, além dos já citados anteriormente, consistiu na busca de saídas para a pressão exercida por estudantes secundaristas por vagas nas universidades públicas, naquela época, muito limitadas e, por isso, intensamente 
disputadas. Tais pressões, aliadas ao contexto político do período, representavam, no entender dos militares, além de sérias ameaças à ordem, pretexto para manifestações antigovernamentais, consideradas, por tal razão, subversivas.

A intensa propaganda midiática relativamente à (suposta) necessidade premente de técnicos para atender os imperativos da produção e a proposta de profissionalização no âmbito do 2 grau, tendo em vista, aparentemente, atender a esses reclamos econômicos, serviu, também como justificativa para tal medida no âmbito educacional. Nesse sentido a profissionalização no 2 grau desempenhou, como salientado por Cunha (1977), papel contendor em relação à demanda pelos cursos superiores públicos. Mas não aplacou a insatisfação das elites e de setores da classe média com o ensino oferecido nas redes públicas que ofertavam o 20 grau, razão pela qual boa parte desse setor da população migrou ou para as escolas privadas ou para as escolas técnicas, em particular as federais, não pela formação técnica em si, mas porque, apesar de sofrerem certo sucateamento na época, tais escolas conservavam, perante tais setores sociais, a imagem historicamente construída de instituições escolares de bom nível. A procura pela escola técnica constituiu-se, assim, não na busca de uma profissionalização no nível do 20 grau, mas numa alternativa à inserção no ensino superior público.

A inserção no ensino superior, todavia foi ganhando configurações diferentes nas décadas seguintes, pois, em função da herança legislativa legada pela ditadura militar, ela foi paulatinamente se deslocando para as escolas superiores privadas que ganharam enorme proporção e poder graças aos incentivos criados pelos entes públicos. Suas vagas já não se destinavam, todavia, apenas a setores de classe, mas, também paulatinamente, passaram a mirar os setores de menor poder aquisitivo, por meio do rebaixamento das mensalidades e, também, da qualidade. Conforme Saviani (2008, p. 298):

esse legado [...] consubstanciou-se na institucionalização da visão produtivista de educação. Esta resistiu às críticas de que foi alvo nos anos de 1980 e mantém-se como hegemônica, tendo orientado a elaboração da nova LDB, promulgada em 1996, e o Plano Nacional de Educação, aprovado em 2001.

A Lei 5.692/1971, por sua vez, teve curta duração, apesar das modificações ocorridas em 1975. A resistência a ela manteve-se de tal forma que, em 1982, a Lei 7.044, praticamente desativou a profissionalização nas escolas de 20 grau a Lei 7.044, apesar de mantê-la como opção, deixando a critério das escolas sua oferta regida quer pelo Parecer 45/1972, quer pelo Parecer 76/1975, assim como as liberou para não cingir-se a nenhuma dessas alternativas, voltando a funcionar conforme os parâmetros estipulados pela Lei 4.024. Tal situação prevaleceu até a promulgação da Lei de Diretrizes e Bases da Educação Nacional (Lei 9.394/1996).

Para compreender o processo que conduziu à concepção e elaboração da LDB acima cabe considerar, inicialmente, que no Brasil da década de 1980, a educação que vinha sendo oferecida a crianças e jovens já era objeto de questionamento, não apenas pela questão da qualidade do ensino oferecido. Dois outros aspectos ganharam evidencia nas décadas de 1970 e 1980, quais sejam, os processos de discriminação de origem social presente no sistema escolar desde sua constituição e a crítica das conexões entre a educação e o desenvolvimento econômico que, nas décadas acima referidas, estavam marcadas pela Teoria do Capital Humano, tendo por base, por exemplo, as pesquisas de Bourdieu e Passeron e de Establet. Os estudos sobre as relações entre a educação e o trabalho que começaram a ganhar corpo nessas décadas tendo por referência as 
produções de Marx e Gramsci dirigiram-se a ambos os aspectos, estimulados, entre outras razões, pelo progressivo esgotamento da ditadura e as perspectivas da democratização do país.

A partir desse questionamento, entidades da sociedade civil apresentaram, no âmbito do primeiro Projeto de Lei da LDB, a proposta de um ensino médio que tivesse por base a concepção da educação politécnica e da escola unitária formuladas, respectivamente, por Marx e Engels (1983) e Gramsci (1979). Todavia, o texto da LDB finalmente aprovado pelo Congresso Nacional em 1996, tendo por base o substitutivo do senador Darcy Ribeiro, consolidou, mais uma vez, a dualidade entre o ensino médio e a educação profissional, negando a perspectiva de formação integral de caráter politécnica e unitária apresentada originalmente pelo deputado Otávio Elísio em 1991 e referendada, nas discussões posteriores, pelo Substitutivo Jorge Hage.

Como se recorda, a Lei 9.394/1996, promulgada no primeiro governo de Frenando Henrique Cardosos situa em dois capítulos diferentes o Ensino Médio e a Educação Profissional. $O$ Decreto 2.208/1997, por sua vez, à guisa de regulamentação do disposto na LDB, promove, sem maiores contestações, a separação entre o ensino médio e o ensino técnico, a qual havia sido rejeitada quando da discussão do Projeto de Lei 1.603/1996.

Tal medida buscou ajustar a educação nacional aos discursos e práticas internacionais relativamente à necessidade da educação rever-se tendo em função dos interesses desencadeados pelas transformações em curso no âmbito do trabalho a partir da década de 1970 - a denominada reestruturação produtiva. Criaram-se, por essa forma, as condições para a instituição de um projeto educacional voltado para a formação dos sujeitos sociais adequados às formas flexíveis de organização do trabalho, não só como produtores, mas, também, como consumidores. Tal projeto materializou-se, como tal, em documentos legais tais como a LDB 9.394/96 e, mais especificamente, no que diz respeito à última etapa da Educação Básica, nas Diretrizes Curriculares Nacionais para o Ensino Médio, de 1998, bem como nas Diretrizes Curriculares Nacionais para a Educação Profissional Técnica de Nível Médio, de 1999.

A proposta acima referida pautou-se, do ponto de vista curricular, tanto na Educação Básica quanto na Educação Superior, pela formação por competências, noção que tem sua origem no universo empresarial, conforme Hirata (1994). Não cabe, neste artigo, uma discussão mais extensa sobre tal proposta de formação. Em outros trabalhos abordei mais detidamente o tema (FERRETTI, 1997, 2000, 2003). Ramos (2000) realizou um estudo minucioso e profundo sobre tal noção.

As proposições educacionais avançadas nos governos de Fernando Henrique Cardoso enfrentaram dois problemas principais. De um lado encontraram dificuldades para materializar-se nas escolas apesar das intensas atividades promovidas pelo MEC tendo em vista a formação continuada de professores, bem como a produção de orientações curriculares e material didático de apoio. Embora tivessem obtido adesões, no geral os professores tenderam a manter as práticas que vinham utilizando. De outro lado, o projeto educacional dos referidos governos sofreu severas contestações por parte de educadores que se posicionavam contra a instrumentalização da educação em geral e não apenas da profissional tendo por referência os interesses dos setores produtivos.

No primeiro governo Lula, alguns dos educadores que contestavam as medidas educacionais adotadas pelos governos de Fernando Henrique Cardoso foram incorporados ao MEC e tentaram transformar as críticas em proposições de política para a educação básica tendo como referência os princípios e postulados da educação politécnica e da escola unitária, enunciados por 
Marx e Gramsci. Os seminários nacionais voltados a professores e gestores do Ensino Médio e do Ensino Técnico, realizados pela então Secretaria do Ensino Médio e do Ensino Técnico (SEMTEC) do MEC em 2003, e a proposição e posterior aprovação do Decreto 5.154/2004 representam movimentos nesse sentido. No entanto, conforme apontam Frigotto, Ciavatta e Ramos (2005) o referido decreto foi marcado pelos embates políticos da época o que impediu a completa revogação do Decreto 2.208/1997, como era a intenção inicial que se voltava predominantemente para o ensino médio integrado, razão pela qual foram mantidas, além dessa forma, a subsequente e a concomitante de articulação entre o ensino médio e a educação profissional de nível técnico, incorporadas posteriormente à LDB. Além disso, a ação do Conselho Nacional de Educação ao invés de elaborar novas Diretrizes Curriculares Nacionais do Ensino Técnico apenas atualizou as promulgadas em 1998 e 1999, mantendo seu espírito.

Por essa razão dois movimentos relativamente simultâneos foram realizados pelos educadores afinados com os fundamentos teóricos e políticos que impulsionaram o Decreto $5.154 / 2004$ na sua origem. Um deles referiu-se à produção de textos, a exemplo do DocumentoBase sobre a Educação Profissional, de 2007 e do Programa Ensino Médio Inovador, de 2009, por meio dos quais foram sugeridas indicações teóricas e formas práticas de implementação do que propunha, em termos de fundamentação, o Decreto 5.154/2004. Outro foi realização de encontros e seminários com a finalidade de submeter à Câmara de Educação Básica do Conselho Nacional de Educação (CNE) proposições de mudanças nas Diretrizes Curriculares, tanto do Ensino Médio quanto da Educação Profissional Técnica de Nível Médio de modo que se adequassem àqueles fundamentos a fim de garantir a formação unitária de caráter politécnico e omnilateral.

Tais movimentos se deram simultaneamente a ações governamentais que resultaram na proposição do PDE e na constituição da Rede Federal de Educação Profissional. A instituição mais preeminente dessa rede é o Instituto Federal de Educação, Ciência e Tecnologia (IF), a que foi atribuída específica, mas não exclusivamente, a implementação da Educação Profissional Técnica integrada ao Ensino Médio sob a forma dos cursos técnicos integrados. Ainda que houvesse a compreensão de que a proposição de mudanças nas diretrizes curriculares seria, por si só, insuficiente para viabilizar a formação unitária, considerou-se que serviria de referência para sua concretização, contribuindo, além disso, para evitar algumas distorções que vinham sendo observadas a respeito dessa concepção.

O desenrolar desse processo teve dois desfechos relativamente diversos. No Caso das Diretrizes Curriculares Nacionais para o Ensino Médio o avanço foi considerável. Os documentos produzidos por educadores e as instâncias destes junto à Câmara de Educação Básica do CNE ensejaram, depois de várias idas e vindas, a proposição de um documento de Diretrizes afinado com as bases teóricas, filosóficas e políticas da escola unitária na perspectiva da formação politécnica e omnilateral. Para fins deste texto cabe ressaltar dois aspectos nele contidos: os pressupostos e fundamentos para um ensino médio de qualidade social; a organização curricular.

O primeiro define com clareza o trabalho, a ciência, a tecnologia e a cultura como dimensões da formação humana, definição absolutamente necessária, pois sendo tais termos polissêmicos, são-lhe atribuídos diferentes significados conforme os interesses políticos e ideológicos dos que o utilizam. $\mathrm{O}$ documento das diretrizes, em consonância com as bases teóricas, filosóficas e políticas anteriormente referidas vincula, de modo claro e necessário, o trabalho humano com a ciência, entendida como "conjunto de conhecimentos sistematizados, produzidos socialmente ao longo da história, na busca da compreensão e transformação da natureza e da 
sociedade", com a tecnologia compreendida como "transformação da ciência em força produtiva ou mediação do conhecimento científico a produção", com a cultura, "compreendida (...) como a articulação entre o conjunto de representações e comportamentos e o processo dinâmico de socialização" (DCNEM, 2011, p. 20). Por isso mesmo o trabalho humano é entendido não da perspectiva estreita do emprego ou do exercício meramente técnico de uma atividade, mas, ontologicamente, como transformação histórica da natureza e do próprio homem, bem como da vida social, a qual tem por base "a convergência entre teoria e prática na ação humana" (idem) Pela mesma razão o documento elege as categorias acima como base para o desenvolvimento curricular no ensino médio.

Um processo educativo que pretenda dar conta de tais relações não pode ser caracterizado, nada menos como o de uma formação integral, ou seja, a que:

não somente possibilita o acesso a conhecimentos científicos, mas também promove a reflexão crítica sobre os padrões culturais que se constitui em normas de conduta de um grupo social, assim como a apropriação de referências e tendências que se manifestam em tempos e espaços históricos, os quais expressam concepções, problemas, crises e potenciais de uma sociedade, que se vê traduzida ou questionada em suas manifestações (ibidem)

Articuladamente a estas formulações o documento elege três grandes princípios orientadores: o trabalho como princípio educativo, a pesquisa como princípio pedagógico e os direitos humanos como princípio norteador.

No primeiro caso o trabalho é entendido, de um lado, na sua perspectiva ontológica como referido anteriormente. De outro lado é compreendido na sua perspectiva histórica, isto é, como o exercício de atividades profissionais num dado contexto, o que implica que a ação educativa articule a perspectiva ontológica com a formação dos indivíduos para a participação no processo produtivo.

A pesquisa como princípio pedagógico é entendida, no documento, a partir de diferentes perspectivas. De um lado como a necessidade de prover os estudantes de um instrumento que os auxilie a lidar com as múltiplas informações a que têm acesso na sociedade contemporânea por intermédio de diversas instituições, entre as quais a própria escola, e de diferentes meios de difusão, particularmente os eletrônicos, de modo que sejam criticadas, problematizadas, refletidas e, finalmente, articuladas para transformarem-se em conhecimento. De outro lado, para defrontarem-se com conhecimentos produzidos em diferentes campos de forma cada vez mais acelerada. Por fim, como cultivo de atitudes de inquietação e curiosidade motivadoras da aquisição de um conjunto de habilidades que os habilite a buscar novos conhecimentos e a "interpretar, analisar, criticar, refletir, rejeitar ideias fechadas, aprender, buscar soluções e propor alternativas" (DCNEM, 2011, p. 22), enfim, pensar, tanto quanto possível, de forma autônoma e ética.

Do ponto de vista do documento, o respeito aos direitos humanos como princípio educativo, tendo por base a Constituição Nacional,

significa fomentar processos que contribuam para a construção da cidadania, do conhecimento dos direitos fundamentais, do respeito à pluralidade e à diversidade de nacionalidade, etnia, gênero, classe social, cultura, crença religiosa, orientação sexual e opção política, ou qualquer outra diferença, combatendo e eliminando toda forma de discriminação. (DCNEM, 2011, p. 23) 
A organização curricular avançada pelo documento tem por base os fundamentos e princípios anteriormente expostos. Esta simples afirmação indica seu caráter de não neutralidade, como ocorre, aliás, com toda e qualquer proposta curricular, dado que esta implica escolha e seleção de seus componentes com base em critérios de variada ordem (política, pedagógica, econômica, cultural, etc.). No caso presente o conhecimento historicamente acumulado é considerado a "matéria prima" do trabalho pedagógico escolar (DCNEM, 2011, p. 39), o que é consistente com a concepção ontológica de trabalho anteriormente apresentada e com o projeto de sociedade e formação humana com que essa se articula.

Isto não significa reiterar a oferta do chamado "currículo enciclopédico", constituído por um conjunto excessivo de disciplinas isoladas. Ao contrário, implica a seleção de "um conjunto de conceitos e categorias básicas", ou em outros termos, "um conjunto necessário de saberes integrados e significativos para o prosseguimento dos estudos, para o entendimento e ação crítica acerca do mundo" (idem, p. 40). Busca-se, por essa forma, superar o a especificidade e a compartimentalização dos saberes enclausurados em disciplinas estanques.

A seleção dos conteúdos, por sua vez é remetida pelo documento à relação entre parte e totalidade na constituição do real. Uma referência importante é o artigo produzido por Ramos (2005) a respeito. Nessa perspectiva e de acordo com o princípio da pesquisa como princípio pedagógico o documento alinha um conjunto de metodologias e estratégias que viabilizam ou estimulam a realização de trabalhos de natureza interdisciplinar que, sem abandonar o aprofundamento conceitual interno às disciplinas, rompam com a fragmentação curricular, articulem-se com a perspectiva do estabelecimento de relações entre partes e totalidade e, ao mesmo tempo, estimulem a participação do aluno na construção do conhecimento.

A exposição anterior pode sugerir que a organização curricular resume-se, no documento, à seleção de conhecimentos e saberes, bem como à eleição de metodologias, seja de ensino, seja de avaliação. Esta é uma falsa impressão, pois o documento chama a atenção também para outro aspecto que é central na organização do currículo na perspectiva delineada, qual seja, a de que ele resulta da construção coletiva e democrática realizada pelos que atuam na escola, sem o que pode transformar-se numa peça meramente técnica e burocrática, alheada da incorporação do conhecimento detido por professores, gestores, funcionários e alunos a respeito da realidade social na qual vivem.

Na discussão da organização curricular há um aspecto para o qual cabe chamar a atenção tendo em vista o que foi discutido até o momento em termos das reformulações pelas quais passou historicamente o que hoje é denominado ensino médio. Trata-se da formalização que usualmente se expressa por meio da denominada "grade curricular". No documento das DCNEM em exame, as disciplinas consideradas obrigatórias pelo CNE estão distribuídas, de acordo com essa formalização, em três grandes áreas Linguagens (Língua Portuguesa, Língua Estrangeira Moderna, Língua Materna - para as comunidades indígenas, Artes e Educação Física); Ciências da Natureza (Biologia, Física, Química); Ciências Humanas (História, Geografia, Filosofia, Sociologia), destacando-se a Matemática como uma disciplina isolada. Os entes federados poderão, a seu critério e tendo em vista peculiaridades locais, acrescentar outros componentes que constituirão a parte diversificada da grade curricular.

Existe, entre a estrutura da "grade curricular" acima referida e aquelas que vigoram desde a Lei 4024/61, uma forte semelhança não apenas no que se refere à distribuição das disciplinas em 
obrigatórias, diversificadas e complementares, mas, particularmente, também forte aproximação entre o conjunto de disciplinas obrigatórias, constitutivas do Núcleo Comum, tanto na Lei 4024, quanto na Lei 5.692/71 e na Lei 9.394/96. Isto sugere que há o reconhecimento de que estas se reportam ao acervo do conhecimento humano a ser preservado e compartilhado com os adolescentes e jovens que vão à escola. Se este aspecto revela-se positivo, as "grades" comportam também uma dimensão preocupante, qual seja, a de que os professores muitas vezes tendem a reduzir o currículo a elas, tomando-as por referência única, independentemente do projeto político-pedagógico a que podem servir, talvez porque representem um "porto seguro" relativamente ao que fazer docente, mesmo que reduzido à mera transmissão de informações. Esta é uma questão a ser examinada mais a fundo não só porque tende a representar um obstáculo à compreensão e ao desenvolvimento do currículo na sua plenitude, mas, também, porque dificulta a superação dos limites que tornam as disciplinas estanques. Esta forma de "organização curricular" tem, ainda, outras consequências, tais como a de estipular o número de aulas semanais de cada professor com desdobramentos para além dos de caráter pedagógico (formas de contratação, salários, alocamento de professores às escolas, relações sindicais).

O processo seguido no que tange à Educação Profissional também foi marcado por trâmites semelhantes aos observados na rediscussão das diretrizes curriculares relativas ao ensino médio, desencadeada após a promulgação do Decreto 5.154/2004. Ou seja, foram realizados seminários, bem como discussões de grupo, dos quais resultaram em documentos por meio dos quais foi intentada não apenas a mesma adequação mas, sobretudo, a consonância entre as diretrizes elaboradas para ambas as esferas. Infelizmente, de modo diverso do que ocorreu em relação às Diretrizes Curriculares Nacionais para o Ensino Médio, as voltadas para a Educação Profissional, apesar do empenho dos educadores, ficaram, mercê do parecer da Câmara de Educação Básica do CNE, marcadas pelo hibridismo entre a concepção político-educacional pautada pela formação politécnica e omnilateral e a fundamentada na formação por competência.

Nos anos mais recentes têm sido observadas na sociedade brasileira ações que promovem o questionamento do projeto educacional do qual as Diretrizes Curriculares Nacionais para o Ensino Médio são expressão. Tais ações são originárias principalmente do setor produtivo, mas também apoiadas por redes públicas de alguns entes federados, ou por entidades que as representam.

Entre essas ações cabe ressaltar a que foi desenvolvida desde maio de 2012, no âmbito da Câmara dos Deputados, pela Comissão Especial destinada a promover Estudos e Proposições para a Reformulação do Ensino Médio (CEENSI). Referida Comissão, depois da realização de várias audiências e seminários públicos aprovou e encaminhou, em 2013, ao então Ministro da Educação Aloizio Mercadante, o relatório elaborado pela Comissão, acompanhado do Projeto de Lei $6840 / 2013$, tendo em vista a reformulação do ensino médio. Considerando sua extensão, nos concentraremos apenas nas críticas a alguns aspectos que nos parecem mais polêmicos. Os interessados poderão consultar os documentos por meios digitais. ${ }^{2}$

O referido projeto apesar de remeter à reformulação do ensino médio, o que supõe a abordagem dos vários aspectos que a ele se referem, centra, de fato, suas atenções no currículo. O pretendido é a modificação da LDB 9394/96 e, por extensão, das Diretrizes Curriculares

${ }^{2} \mathrm{O}$ projeto de Lei e sua justificativa podem ser acessados por intermédio de www.camara.gov.br/proposicoes Web/fichadetramitacao?idProposicao $=602570$ 
Nacionais do Ensino Médio aprovadas em 2011, portanto, apenas um ano antes do início dos trabalhos da Comissão Especial. Basicamente, propõe-se uma base nacional comum centrada em quatro áreas do conhecimento (linguagem, matemática, ciências da natureza e ciências humanas) sendo a terceira série flexibilizada conforme as "ênfases" nas diferentes áreas. Isto é, nessa série os alunos se dividiriam, segundo suas preferências, entre as áreas propostas, ou ainda, optariam por uma formação profissional. Tal flexibilização é reforçada por outra proposição constante do PL 6840, qual seja, a de que as avaliações e processos seletivos que dão acesso ao curso superior se façam tendo por base as opções formativas escolhidas pelos alunos na $3^{a}$ série.

Apesar de ser desejável a existência de uma base nacional comum, deve-se considerar, inicialmente, que ela é mais pobre do que a constante das atuais DCNEM. Por outro lado, a obrigatoriedade da opção na terceira série promove a fragmentação do processo formativo que antecipa para a Educação Básica (portanto para todos) processos de especialização que a comprometem e ferem a proposta de integração constante das atuais Diretrizes Curriculares para o ensino médio. Causa espécie, por outro lado, a proposta da "ênfase" na formação profissional, posto que a legislação atual prevê tal formação por meio de diferentes formas de ensino técnico entre as quais ressalta o ensino médio integrado à educação profissional.

Dois outros pontos questionáveis do PL 6.840/2013 referem-se à proposta de oferta do ensino médio em tempo integral (sete horas diárias) no período diurno e a medidas referentes ao ensino médio noturno. A oferta do EM em tempo integral é, em tese, positiva na medida em que permite maior atenção dedicada aos jovens que o frequentam. No entanto, do ponto de vista da realidade socioeconômica da grande parte dos jovens brasileiros oriundos dos setores populares, representa uma forma de exclusão do EM ministrado no período diurno, dado o fato de que parcela significativa da população jovem do país trabalha, seja para contribuir para a renda familiar, seja para suprir suas próprias necessidades. É, portanto, nesse contexto, medida discricionária, que institui um EM diferenciado para uma população jovem com melhores condições de vida e relega, o curso noturno, ainda mais, aos setores populares, ao arrepio do que propôs a CONAE para o PNE.

Aprofunda-se o caráter discriminatório da proposta quando esta reivindica a ampliação do número de escolas que possam ofertar o EM diurno em tempo integral, em contraponto à simples manutenção do número de cursos noturnos. Por outro lado, a discriminação é reiterada quando o PL 6840 propõe a não aceitação de matrículas de jovens menores de 18 anos sob a alegação de que nem todos os que demandam a realização dos cursos no horário noturno teriam necessidade de fazê-lo nesse período.

Além disso, cabe considerar a relação entre extensão da jornada escolar diária (tempo integral, conforme o PL 6.840) e a elevação significativa na qualidade do ensino ofertado suposta pelo documento. Dependendo das circunstâncias tal elevação pode ocorrer. No entanto, mantidas, por exemplo, as condições precárias existentes em inúmeras redes de ensino estaduais no que respeita à infraestrutura, aos equipamentos escolares, ao funcionamento, à disponibilidade de professores, etc., a mera extensão do tempo de permanência nada ou muito pouco acrescentará à qualidade do ensino. Por outro lado a extensão da jornada escolar não implica, diretamente, formação integral como implicitamente sugere o PL 6.840, incorrendo uma confusão muito frequente no senso comum. As atuais DCNEM que o PL 6.840 pretende modificar explicitam claramente no que consiste a formação integral tal como avançado pela perspectiva da escola unitária de inspiração gramsciana. A negação dessa perspectiva é absolutamente clara no projeto 
de lei em várias das suas indicações, tais como as discutidas anteriormente ou como a que empresta relevo aos temas transversais na organização curricular. Como assevera o Manifesto dos educadores em relação a esta última, as atuais diretrizes curriculares do ensino médio

preconizam que haja uma estreita relação entre conhecimento tratado na escola e sua relação com a sociedade que o produz. Deste modo, não cabe falar em "temas transversais" já que todo conhecimento, ao estar vinculado ao contexto social que o produziu, adquire sentido e expressão na construção da autonomia intelectual e moral dos educandos.

A proposta de oferta do ensino médio em tempo integral traz em seu bojo, no entanto, algo de positivo: a da vinculação dos professores em tempo integral às escolas que oferecessem ensino médio na jornada estendida. No meu entender, sem que fosse sua intenção, a justificativa do projeto aponta para um aspecto que deveria ser considerado não apenas para o ensino médio, mas para toda a educação básica, independentemente da escola ter seus cursos funcionando em tempo integral. Trata-se da defesa do exercício da jornada de trabalho do professor numa única escola, medida que pode produzir muitos avanços na qualidade do ensino aí oferecido, embora não seja, isoladamente, condição suficiente para tal. Outro ponto positivo da justificativa diz respeito à proposta de criação de programas de financiamento para a construção de novas escolas e o aparelhamento das já existentes melhorando sua infraestrutura.

As severas críticas de educadores e suas entidades ao PL 6.840/2013 culminaram com a criação do Movimento Nacional em Defesa do Ensino Médio o qual elaborou uma Petição Pública contra o Projeto de Lei, dirigida à Presidência da República, Ministério da Educação, Câmara dos Deputados e Conselho Nacional de Educação assinado por esses mesmos profissionais e entidades. O Movimento realizou, durante o ano de 2014, conversações com o MEC e com os propositores do PL 6840, os quais deliberaram promover sua revisão. Esta foi aprovada em sessão da Comissão Especial realizada 16 de dezembro de 2014, a qual, na ocasião deu por encerrada suas atividades.

A revisão aprovada contempla algumas das críticas feitas, ao mesmo tempo em que desconsidera outras ou mantém proposições criticadas alterando, por vezes, sua redação. ${ }^{3}$ Nos parágrafos seguintes, as discussões sobre as modificações do PL serão agrupadas em torno dos temas, lembrando que as proposições do PL 6.840 referem-se a alterações a serem promovidas na LDB 9.394/1996: extensão da jornada escolar; organização curricular; ENEM; acesso ao Ensino Superior; relação público-privado; formação de docentes do ensino médio.

No que se refere à extensão da jornada escolar, o substitutivo abandona a proposta de obrigatoriedade do tempo integral para o ensino médio diurno presente na versão inicial, o que é um ganho. Todavia o substitutivo propõe, de acordo com o inciso VIII do artigo 24, bem como do artigo 35-A, a possibilidade da efetivação progressiva do ensino médio de tempo integral, a critério dos sistemas de ensino, alinhando-se com a meta 6 do Plano Nacional de Educação. A questão que permanece, ainda que sejamos, em tese, favoráveis à extensão da jornada escolar é a de que os ganhos sociais e educacionais que dela se espera dependem, de um lado, da criação de condições econômico-sociais que permitam a adolescentes e jovens dos setores populares a frequência ao ensino médio de tempo integral e, de outro, que essa extensão se faça com base em condições

\footnotetext{
${ }^{3} \mathrm{O}$ inteiro teor do substitutivo do PL 6.840 aprovado em 16/12/2014 pode ser acessado por meio do endereço eletrônico indicado na nota 3.
} 
institucionais que estimulem a formação com qualidade, na medida em que esta não é necessariamente resultado daquela.

No tocante à organização curricular o substitutivo propõe alterações substantivas no atual artigo 36 da LDB. Este artigo, na redação do substitutivo, contém, além do caput, dezesseis parágrafos Ele é, na verdade, o fulcro do substitutivo do PL 6840, razão pela qual, embora mantenha elementos afinados com a atual LDB e com as DCNEM vigentes, não presentes na sua formulação original, insiste, no espírito e, de alguma forma, na letra, na perspectiva das especializações precoces que foram alvo da crítica dos educadores que assinaram o Manifesto anteriormente referido.

Em primeiro lugar é mantida, no caput do artigo, a proposta de que os currículos do ensino médio sejam organizados tendo em vista as quatro áreas de conhecimento que já estavam presentes na versão original: linguagens, matemática, ciências da natureza e ciências humanas. A base nacional comum do ensino médio deverá abranger tais áreas ( $\S 10$ ) e será composta, conforme o § 70, pelos componentes curriculares de tal base, conforme definido pelas DCNEM de 2012. A inclusão desses componentes, não presentes na versão original, constitui um ganho, assim como a menção, no $\S 20$, de que as propostas curriculares serão articuladas tendo como referência as "dimensões do trabalho, da ciência, da tecnologia e da cultura como eixo integrador entre os conhecimentos de diferentes naturezas, contextualizando-os em sua dimensão histórica e em relação ao contexto social contemporâneo", sem, no entanto, haver menção aos seus fundamentos e à sua relação com a formação integrada na perspectiva unitária.

Esta não é uma questão de somenos, dada a redação do §8o quando este faz referência à inclusão de "outros conteúdos curriculares a critério dos sistemas e das instituições de ensino [...] incluídos na parte diversificada dos currículos [...] devendo ser tratados, preferencialmente (nosso grifo), de forma transversal e integradora" ou, segundo o voto do relator, como temas transversais. Tais temas, objeto da crítica no PL original, ressurgem, da mesma maneira como as "ênfases", sob outra forma, a meu ver mais problemática, porque associados à integração. A ausência da referência teórico-epistemológica e filosófica à integração, apontada no parágrafo anterior, cria, a meu ver uma perigosa zona de penumbra, pois a integração é referida como algo quase sinônimo da transversalidade.

Constitui também um ganho a indicação, no $\S 5$ 으, de que os componentes da base nacional comum e seus conteúdos "deverão ser desenvolvidos nos currículos de todas as séries do ensino médio" (nosso grifo) posto que isso significa que as "ênfases" diferenciadas na 3a série, propostas na versão original, não mais farão parte do percurso formativo obrigatório do ensino médio, atendendo, portanto, as observações críticas feitas a respeito. No entanto, os artigos 9o e 11응 deixam claro que a perspectiva das "ênfases" não desapareceu, mas apenas mudou de figura. Deixam de ser obrigatórias e de tomar o lugar da base comum na 3a série. Esta é mantida no decorrer de todo o ensino médio e as "ênfases" passam a ser optativas para os alunos sem que se esclareça a partir de que momento do curso.

A redação do artigo 9o permite supor que tais opções possam ocorrer desde o início do curso: "assegurada a formação geral, definida na base nacional comum, e com vistas ao disposto no inciso VIII do artigo 24, serão ofertadas as seguintes opções formativas, de livre escolha do aluno [...]", o que é referendado pelo voto do relator quando este afirma que tais opções podem ocorrer a partir da 1 a série do curso 0 referido inciso diz respeito à extensão da jornada 
(configurando o tempo integral), o que conduz à suposição de que os componentes da base comum serão lecionados no "turno" do período escolar e as "ênfases" serão oferecidas no "contra-turno" deste, juntamente com as disciplinas da parte diversificada do currículo. O substitutivo pretende, por essa forma, e ao mesmo tempo, conferir atenção às críticas sem abrir mão das "ênfases". 0 mesmo raciocínio se aplica aos alunos do ensino médio noturno, que a ele poderão acorrer, por força do substitutivo, sem a restrição de idade imposta pela versão original do PL 6840. Posto que, nesse caso, não cabe a extensão da jornada, o artigo 35-B do substitutivo define que, cumprida a formação geral, os sistemas de ensino, deverão facultar "ao aluno do ensino médio noturno cursar em outro turno uma das opções formativas" constantes do artigo 9․

Situação mais complexa é a configurada pelo artigo 11‥ De acordo com este, "observada a base nacional comum obrigatória e a critério dos sistemas de ensino, poderá ser ofertada ao aluno do ensino médio uma formação técnica alternativa às opções estabelecidas no artigo 9o". Isto significa, ao fim e ao cabo, o estímulo à formação técnica concomitante, a exemplo do que ocorria sob o Decreto 2.208/1997 e vem sendo posto em prática pelo governo de São Paulo desde 2012. Além disso, o substitutivo reitera o artigo $36-\mathrm{E}$, presente na versão original, segundo o qual a educação profissional técnica, na forma proposta, poderia ser realizada sob a forma de parceria e cooperação. Tal parceria tem sido posta em prática, inclusive nos cursos técnicos, por meio do Pronatec. Este programa, como se sabe, constitui uma das formas pelas quais é operada a transferência de recursos públicos para a iniciativa privada, onerando o tesouro nacional, sem que haja avaliações consistentes e confiáveis sobre os resultados educacionais almejados. A recente crise econômica e a necessidade de contenção de gastos que gerou levou o governo Dilma a rever tal política, inclusive no que diz respeito à concessão de recursos a instituições privadas pouco credenciadas.

Dois parágrafos do substitutivo (15 e 16ㅇ) relativos a formas de organização da educação básica parecem-me obscuros. De um lado definem a possibilidade da organização por ciclos ou créditos de terminalidade específica ( $\$ 15^{\circ}$ ). De outro apontam para a certificação de etapas do ensino médio com terminalidade específica. O termo chave neste caso é "terminalidade específica". Se este termo é outra forma de referir-se às ênfases, o que está sendo indicado é a possibilidade da certificação não apenas como conclusão desse nível de ensino em geral, mas como conclusão relacionada a um campo, ou "ênfase" específica, o que poderá, posteriormente, redundar em diferenciações entre os concluintes do ensino médio com respeito à sua formação, com implicações para sua inserção em cursos de nível superior, interpretação que, a meu ver, é reforçada pela redação do $\S 20$ adicionado pelo substitutivo ao artigo 44 da LDB.

A manutenção das "ênfases" na forma prevista coloca em questão a perspectiva da formação integrada. Ainda que estas venham a ser desenvolvidas na mesma escola (exceção feita à educação profissional) e, talvez, pelos mesmos professores que lecionam os componentes da base comum, apartam-se desta, como uma espécie de "especialização" numa das áreas de conhecimento listadas no caput do artigo 36. Ora, tal "especialização" tenderá, a meu ver, pela própria valorização das ênfases por parte do PL 6.840, a ganhar precedência sobre a perspectiva da construção interdisciplinar do conhecimento entre os diferentes componentes curriculares, na linha sugerida pelos $\S 2$ e 6을 do substitutivo. A "especialização" parece visar, de um lado, o melhor desempenho dos alunos nas disputas pelo acesso ao ensino superior e, de outro, os interesses dos setores produtivos no sentido da formação dos profissionais que thes interessam, como vem 
ocorrendo historicamente na educação brasileira, mais do que a formação plena, omnilateral e básica dos alunos do ensino médio.

Felizmente o substitutivo retirou a formação dos professores que virão a atuar no ensino médio do âmbito das quatro áreas de conhecimento previstas no original do PL 6.840 (§ 8, acrescido ao artigo 62 da Lei 9.394/1996). O alargamento dessa formação tendo por referência a base nacional comum pode contribuir para que o olhar desses professores sobre a educação básica e sobre os jovens aos quais ela é ofertada se enriqueça, permitindo-Ihes o desenvolvimento de educação de qualidade.

Por fim, cabe menção ao fato de que a leitura conjunta não apenas do PL, mas, também, do relatório e do voto do relator que o encaminham, indica que proposições contidas no primeiro são, de certa forma, negadas, principalmente no texto do relatório, pois este repete formulações que serviram de justificativa ao projeto original, mas não se encontram presentes no substitutivo. É possível que se trate apenas de um problema de forma, mas não se deve esquecer que as justificativas de um projeto revelam o espírito que o anima.

O PL 6.840 é, mesmo na sua versão reformulada, a exemplo do que ocorreu com as Diretrizes Curriculares Nacionais para a Educação Profissional Técnica de Nível Médio promulgada em 2012, um texto hibrido que, face às críticas, extirpou formulações mais polêmicas, incorporou elementos das Diretrizes Curriculares Nacionais para o Ensino Médio aprovadas em 2011, mas não abriu mão do que era mais caro a seus propositores: a escolarização em tempo integral e o desenvolvimento do ensino médio tendo em vista não prioritariamente a formação básica, politécnica e omnilateral, em suma, a formação efetivamente integral, mas a de caráter mais específico e imediatista, tendo em vista, num primeiro momento, o encaminhamento para os cursos superiores e, ao final, a contribuição para as demandas que interessam à economia capitalista.

\section{REFERÊNCIAS BIBLIOGRÁFICAS}

1. BRAGHINI, Katya Mitsuko Zuquim. O ensino secundário brasileiro nos anos 1950 e a questão da qualidade do ensino. Dissertação de Mestrado. Pontifícia Universidade Católica de São Paulo, Programa de Pós-Graduação História, Política, Sociedade, 2005.

2. CUNHA, Luiz Antonio. Política educacional no Brasil: a profissionalização no ensino médio. Rio de Janeiro, Eldorado, 1977.

3. FERNANDES, Florestan. O desafio educacional. São Paulo: Cortez: Autores Associados, 1989.

4. FERRETTI, Celso. Formação profissional e reforma do ensino técnico no Brasil: anos 90. Educação \& Sociedade, Campinas, n. 59, p. 225-269, 1997.

5. FERRETTI, Celso; SILVA JR., João dos Reis. Educação Profissional numa sociedade sem empregos. Cadernos de Pesquisa, São Paulo, Fundação Carlos Chagas, n. 109, p. 43-65, 2000.

6. FERRETTI, Celso. A reforma do ensino médio: uma crítica em três níveis. Linguagem, Educação e Sociedade, Universidade Federal do Piauí, p. 41-49, 2003.

7. FRIGOTTO, Gaudêncio; CIAVATTA, Maria; RAMOS, Marise Nogueira (orgs.). Ensino Médio Integrado: concepções e contradições. São Paulo: Cortez Editora, 2005.

8. GRAMSCl, Antonio. Os intelectuais e a organização da cultura. 3. ed. Rio de Janeiro: Civilização Brasileira, 1979. 
9. HIRATA, H. 1994. Da polarização das qualificações ao modelo de competência. In: FERRETTI, C. J. et al. (orgs.) Novas tecnologias, trabalho e educação: um debate multidisciplinar. 1a ed.. Petrópolis: Vozes, p. 128-142.

10. MACHADO, Celso de Souza. O ensino de Sociologia da escola secundária brasileira: levantamento preliminar. Revista da Faculdade de Educação, São Paulo 13(1): 115-142, jan./jun., 1987.

11. MARX, Karl; ENGELS. Friedrich. Textos sobre educação e ensino. São Paulo, Moraes, 1983.

12. RAMOS, Marise Nogueira. A pedagogia das competências. São Paulo, Cortez, 2001.

13. Possibilidades e desafios na organização do currículo integrado. In: FRIGOTTO, Gaudêncio; CIAVATTA, Maria; RAMOS, Marise Nogueira (orgs.). Ensino Médio Integrado: concepções e contradições. São Paulo: Cortez Editora, 2005.

14. SAVIANI, Dermeval. O choque teórico da politecnia. Trabalho, Educação e Saúde, Revista da EPSJV/FIOCRUZ, Rio de Janeiro, Editora Fiocruz, n 1, 2003, p. 131-152.

15. SAVIANI, Dermeval. O legado educacional do regime militar. Campinas, Cadernos Cedes, Campinas, vol. 28, n. 76, p. 291-312, set/dez., 2008.

16. SOUZA, Rosa Fátima de. A renovação do currículo do ensino secundário no Brasil: as últimas batalhas pelo humanismo (1920 -1960). Currículo sem Fronteiras, v.9, n.1, pp.72-90, Jan/Jun 2009.

17. WEREBE, Maria José Garcia. Grandezas e misérias do ensino no Brasil. São Paulo: Difusão Européia do Livro, 1968. 